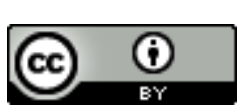

\title{
UNIVERSIDADES DE CLASSE MUNDIAL E A IDEOLOGIA DA EXCELÊNCIA: TENDÊNCIAS GLOBAIS E LOCAIS
}

\begin{tabular}{c}
\hline WORDL CLASS UNIVERSITIES AND THE IDEOLOGY OF EXCELLENCE: \\
GLOBAL AND LOCAL TRENDS \\
\hline UNIVERSIDADES DE RANGO MUNDIAL Y LA IDEOLOGÍA DE LA EXCELENCIA: \\
TENDENCIAS GLOBALES Y LOCALES \\
\hline
\end{tabular}

\section{Lara Carlette Thiengo \\ Lucídio Bianchetti}

RESUMO: Neste trabalho, que resulta de pesquisa de doutorado, analisa-se o modelo de Universidade de Classe Mundial (UCM), a partir das orientações dos Organismos Internacionais (OI), em especial o Banco Mundial (BM), e seus experts e ainda como esta concepção vem ganhando força em vários países, grupos e blocos, incentivando a promoção de programas, políticas e projetos, inclusive, no Brasil. Em termos metodológicos, utilizou-se a análise documental, considerando-se que a investigação sobre as tendências e manifestações da UCM pressupõe a compreensão da totalidade histórica e social. Conclui-se que o modelo de UCM, fundamentado pela Ideologia da Excelência, é uma tendência global que vem sendo utilizada como um arquétipo com o qual se induz à competitividade internacional e eleva-se ao paroxismo a diferenciação/hierarquização entre e intra instituições em diferentes escalas, bem como incita transformações na própria concepção de universidade.

Palavras-Chave: Universidade de Classe Mundial. Ideologia da Excelência. Política Educacional. Organismos Internacionais. Iniciativas de Excelência.

\begin{abstract}
This paper, which results from a doctoral study, analyzes the World Class University model, based on the guidelines of international organizations, especially the World Bank and its experts. It examines how this concept has been gaining strength in Brazil and other countries, groups and blocks, encouraging the promotion of programs, policies and projects. The methodology used included document analysis, recognizing that the investigation of the trends and manifestations of the World Class University presupposes an understanding of the historical and social totality. The article concludes that the World Class University model, based on an "Ideology of Excellence", is a global trend that serves as an archetype to induce international competitiveness. This intensifies the differentiation and hierarchization between and within institutions on different scales, and leads to transformations in the very concept of university.
\end{abstract}

KEYWORDS: World Class University. Ideology of Excellence. Educational politics. International Organizations. Initiatives of Excellence.

RESUMEN: En este artículo, que resulta de investigación de doctorado, se analiza el modelo de Universidad de Rango Mundial (URM), a partir de las orientaciones de los Organismos Internacionales (OI), en especial el Banco Mundial (BM), y sus expertos y aún como esta concepción viene ganando fuerza en varios países, grupos y bloques, incentivando la promoción de programas, políticas y proyectos, inclusive, en Brasil. En términos metodológicos, se utilizó el análisis documental, considerando que la investigación sobre las tendencias y manifestaciones de la URM presupone la comprensión de la totalidad histórica y social. Se concluye que el modelo de URM, fundamentado por la Ideología de la Excelencia, es una tendencia global que viene siendo utilizada como un arquetipo con el que se induce a la competitividad internacional y se eleva al paroxismo la

\footnotetext{
${ }^{1}$ Submetido em: 16/05/2018 - Aceito em: 16/06/2018 - Publicado em: 18/10/2018
}

\begin{tabular}{l|c|c|c|c|c|c} 
(C) Rev. Educ. Perspec. & Viçosa, $M G$ & v.9 & n.1 & p.241-258 & maio/ago. 2018 & eISSN 2178-8359 \\
\hline
\end{tabular}


diferenciación / jerarquización entre e intra instituciones en diferentes escalas, así como incita transformaciones en la propia concepción de la universidad.

PAlABRAS Clave: Universidad de la clase mundial. Ideología de la Excelencia. Política Educativa. Organismos Internacionales. Iniciativas de Excelencia.

\section{INTRODUÇÃO}

A busca pela 'excelência' acadêmica e científica vem afirmando-se, de maneira cada vez mais expressiva, no cenário da educação superior em todo mundo. Especialmente a partir dos anos 2000, diferentes atores, quais sejam, OIs, experts e think tanks, bem como diferentes estratégias, dentre as quais se destacam os rankings, têm atuado e sido utilizadas no sentido de corroborar a necessidade da concretização dessa 'excelência' a partir de um novo modelo de universidade, as World Class University, também chamadas de Universidades de Excelência e/ou Universidades de Classe Mundial (UCM) ${ }^{\mathrm{i}}$.

Compreendemos, pois, que a emergência/difusão deste modelo de universidade, faz parte de um processo mais amplo de reformas da educação superior que vêm ocorrendo nas últimas décadas e têm como características centrais: a expansão dos sistemas de educação superior; a internacionalização a partir dos processos de mobilidade e cooperação; e o aprofundamento da diferenciação e flexibilização das Instituições de Educação Superior (IES) e a ampliação das modalidades de ensino e pesquisa. Essas transformações estão articuladas à reconfiguração do papel do Estado e às aceleradas transformações decorrentes do processo de mundialização do capital (CHESNAIS, 1996), considerando as novas finalidades requeridas à universidade no âmbito do regime de predominância financeira: a produção de 'conhecimento matéria-prima' (SILVA JÚNIOR, 2017).

A partir destas considerações, neste trabalho, dedicamo-nos a analisar o que é uma UCM a partir dos documentos elaborados e/ou editados pelos Organismos Internacionais (OI): Banco Mundial (BM); Organização das Nações Unidas para a Educação, a Ciência e a Cultura (Unesco) e Organização para a Cooperação e Desenvolvimento Económico ou Econômico (OCDE) a partir da década de 2000 e ainda explicitar como esta concepção vem ganhando força em vários países, grupos e blocos, incentivando a promoção de programas, políticas baseados no aprofundamento da diferenciação institucional/educacional, inclusive, no Brasil. Em termos metodológicos, utilizamos a análise documental, considerando-se que a investigação sobre as tendências e manifestações da UCM pressupõe a compreensão da totalidade histórica e social, com seus condicionantes estruturais e conjunturais, isto é, inserida no contexto da crise estrutural do sistema vigente. 
Defendemos, pois, que analisar a concepção de UCM não se trata unicamente de compreender a constituição de universidades 'de ponta', mas também de apreender como este modelo difunde uma 'Ideologia da Excelência', que vem sendo incorporada por governos, instituições, docentes e discentes, redimensionando a concepção e as finalidades da instituição universitária.

\section{UNIVERSIDADE DE CLASSE MUNDIAL: O QUE DIZEM OS ORGANISMOS INTERNACIONAIS}

De saída, é importante considerar que ao analisar o conjunto de documentos que tratam da educação superior na década de 1990, percebemos que a lógica da nominada 'diversificação' já compunha as orientações dos OIs, enfatizando a diferenciação entre as universidades de pesquisa e as universidades de ensino. Contudo, o modelo de UCM é definido e passa a ser explicitamente difundido a partir da primeira década de 2000. Desse modo, os documentos analisados para esta pesquisa foram: Salmi (2009) e Altbach e Salmi (2011), ambos editados pelo BM; Sadlak e Cai (2009), editado pela Unesco e, OCDE (2014)

Ao considerar este conjunto de documentos, apreendemos que o modelo proposto refere-se à constituição de universidades ou grupo de universidades que tenham um propósito específico, que seria o de representar globalmente o ensino superior nacional em sua capacidade de gerar desenvolvimento econômico e conhecimento na área científica, tecnológica e de inovação. Neste sentido, as UCM, além de produzirem pesquisas, devem responsabilizar-se pela formação de cientistas e pesquisadores que, espera-se, ocuparão importantes postos de trabalho na economia e nos processos de geração de conhecimento, em apoio aos sistemas nacionais de inovação.

Neste sentido, no documento publicado pelo BM (SALMI, 2009), a UCM é identificada a partir de um conjunto de características ou (pré)condições, tais como: i) uma alta concentração de talentos (professores e alunos); ii) abundantes recursos para oferecer um ambiente de aprendizado rico e conduzir pesquisa avançada; e iii) características favoráveis de governança que incentivem visão estratégica, inovação e flexibilidade, permitindo que as instituições tomem decisões e gerenciem recursos sem se sobrecarregarem com burocracias. 


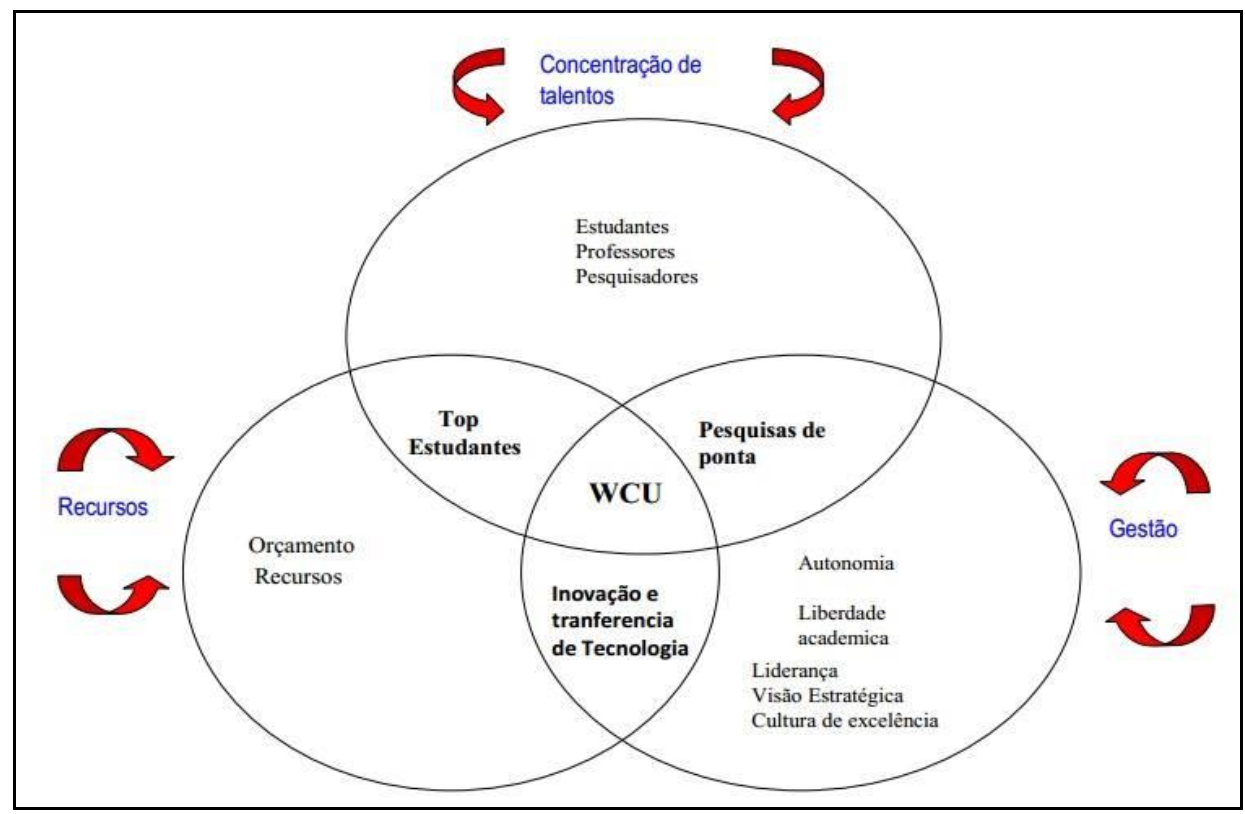

Figura 1. Modelo de UCM

Fonte: Salmi (2009)

De acordo com o documento editado pela Unesco (SADLAK; CAI, 2009), a UCM é apresentada como parte de um novo paradigma de ensino superior. Assim, estas instituições configurar-se-iam como "lugares especiais onde novas ideias e descobertas originam investimento fundamental para o conhecimento e as pessoas" (SADLAK; CAI, 2009, p. 16), uma vez que, com o "nível atual de massificação do ensino superior, torna-se inadvertidamente mais claro do que nunca a necessidade de se voltar novamente para a 'excelência acadêmica' e 'diferenciação de qualidade' a nível global, nacional e local" (SADLAK; CAI, 2009, p. 11).

Sendo assim, "a Universidade de Classe Mundial não está relacionada simplesmente a um 'termo da moda' [...], mas tem como objetivo desenvolver a capacidade necessária para competir no mercado global de ensino superior, através da aquisição e criação de conhecimento avançado" (SALMI, 2009, p. 17). Para construir esse novo modelo de universidade, são apresentadas como estratégias: a) melhorar um número pequeno de universidades existentes que têm o potencial para se destacar; b) incentivar um número de instituições existentes para se unirem, transformando-se em uma nova; c) criar novas UCM a partir de zero (SALMI, 2009).

Cada uma dessas estratégias é analisada nos documentos, indicando as 'melhores possibilidades' para os diferentes governos e instituições. Nesse contexto, são utilizados de forma recorrente resultados de rankings e análises de exemplos de sucesso, que poderiam 'inspirar' outros formuladores de política. Contudo, todos podem aspirar, com reais chances de alcançar, o status de classe mundial, conforme preconizado por esses OI. 
Especificamente em relação à questão levantada, podemos afirmar que há convergência por parte dos OIs no entendimento de que as distinções entre os graus de desenvolvimento econômico e científico dos países 'influenciam' na forma como estes devem traçar suas estratégias para alcançar o status de classe mundial, embora este posicionamento apresente-se ora mais sutil, ora menos, considerando a especificidade da produção de cada documento. Entretanto, compreendemos que 'o horizonte' da excelência e a promoção da competitividade compõem, fundamentalmente, a 'mensagem' implícita em tais publicações, o que pode ser percebido no excerto a seguir:

Instituições acadêmicas em países pequenos ou pobres não podem competir com as Oxfords ou Harvards das nações industrializadas. Mesmo assim, a maioria dos países pode suportar pelo menos uma universidade de qualidade suficiente para participar de discussões internacionais da ciência e da cultura e realizar pesquisas em uma ou mais áreas relevantes para o desenvolvimento nacional (SADLAK; CAI, 2009, p. 67).

Ganha destaque nos documentos a constatação de que um número crescente de países e pessoas está se juntando à corrida para construir UCM por meio do estabelecimento de iniciativas especiais, tais como a concessão de fundos adicionais para universidades selecionadas. É justamente a partir desta verificação que a OCDE passa a tratar mais especificamente da temática, no documento Promoting Research Excellence: New Approaches to Funding (OCDE, 2014). A publicação apresenta novas evidências sobre a forma como os governos estão orientando fundos públicos de pesquisa para instituições de ensino e de investigação, além de divulgar as Research Excellence Initiatives (REI) ${ }^{\mathrm{iii}}$ como novo instrumento de financiamento para a criação de Centros de Excelência (CoEs), entidades com objetivos de pesquisa que se diferem em natureza de outras instituições de pesquisa.

Compreendemos então que as REIs estão alinhadas à concepção de UCM apresentada pelo BM (SALMI, 2009; 2011) e pela Unesco (SADLAK; CAI, 2009), uma vez que se orientam a partir das mesmas características e objetivos centrais - ciência de excelência, atração de talentos, níveis diferenciados de financiamentos e gestão flexível. Ou seja, são expressões do consenso acerca da excelência acadêmica e científica contidas na concepção de UCM.

Outra questão importante apontada pelos OIs e seus experts são os rankings internacionais das universidades, uma vez que a avaliação é componente essencial para a construção de uma UCM, haja vista que a 'qualidade' das instituições é expressa de acordo com o atendimento de critérios previamente estabelecidos.

Em linhas gerais, compreendemos que, não obstante as especificidades entre os OIs (e seus experts), o modelo de UCM está posto e faz parte de uma agenda política global, indicando, nos curto e médio prazos, o remodelamento dos sistemas nacionais de pesquisa. As principais

\begin{tabular}{l|c|c|c|c|c|c} 
() Rev. Educ. Perspec. & Viçosa, $M G$ & v.9 & n.1 & p.241-258 & maio/ago. 2018 & eISSN 2178-8359 \\
\hline
\end{tabular}


características deste modelo, de acordo com os referidos documentos, são analisadas no item a seguir.

\section{CARACTERÍSTICAS CENTRAIS DA UNIVERSIDADE DE CLASSE MUNDIAL}

\section{Internacionalização e 'atração de talentos'}

A internacionalização é apresentada como um dos principais fatores na 'busca pela excelência', uma vez que é importante na concentração de talentos, ou seja, "a grande afluência de estudantes estrangeiros pode ser fundamental para melhorar o nível acadêmico da população estudantil" (SALMI, 2009, p. 46). Desse modo, "os países estão atraindo professores e pesquisadores de renome para produzir resultados de pesquisa de ponta em todos os campos acadêmicos e, consequentemente, estão criando departamentos universitários de classe mundial" (SADLAK; CAI, 2009, p. 15).

Segundo Altbach et al. (2010), na maioria dos países que compõe o eixo dinâmico do capital as trajetórias individuais das carreiras docentes são refletidas em salários diferenciados, o que, na perspectiva dos autores, é fundamental para o desenvolvimento futuro de uma 'cultura de excelência'. Como consta na publicação da Unesco analisada há evidências crescentes de que os desenvolvimentos econômicos dependem cada vez mais de trabalhadores talentosos e altamente qualificados, particularmente aqueles que possuem as habilidades científicas e de engenharia necessárias. As redes de pesquisa, incluindo instituições de diferentes países e também o setor privado, neste contexto, são incentivadas por apresentarem-se cada vez mais úteis.

Cabe ressaltar que a centralidade adquirida pela concentração de talentos para o modelo de UCM expressa pelo menos dois movimentos que nos ajudam a compreender o papel deste modelo de universidade no sistema vigente. O primeiro deles é o mercado criado no âmbito da mobilidade internacional de alunos e docentes, que, de acordo com Altbach et al. (2010), representa uma indústria de 45 bilhões de dólares, com capacidade para triplicar esse valor até o ano de 2020. Outros dados que evidenciam este cenário são os índices de mobilidade acadêmica do International Institute of Education (IIE), os mais altos das últimas séries históricas (SILVA JÚNIOR, 2017).

O segundo movimento está relacionado à formação para o trabalho complexo, que deve levar em consideração, durante a sua realização, as áreas estratégicas dos distintos países, em consonância com o processo de mundialização do capital. De acordo com Sguissardi (2014) e Silva Júnior (2017), este novo momento do capitalismo caracteriza-se pela descentralização

\begin{tabular}{l|c|c|c|c|c|c} 
() Rev. Educ. Perspec. & Viçosa, $M G$ & v.9 & n.1 & p.241-258 & maio/ago. 2018 & eISSN 2178-8359 \\
\hline
\end{tabular}


de grandes empresas, cujas unidades multiplicam-se e espalham-se por diversas regiões e países em busca de menores custos e maiores vantagens quanto à força de trabalho, matéria prima, legislação trabalhista mais flexível, demandando para tanto universidades que pesquisem e formem força de trabalho especializada.

Afirma-se também o imperativo da Língua Inglesa no processo de constituição das Universidades de Excelência, já que a principal característica desse modelo de universidade é a internacionalização.

Em consonância com o exposto, evidencia-se a necessidade de um 'novo tipo de docente', que esteja inserido em uma 'cultura da investigação' em que a 'produtividade científica' deve ser alta (ALTBACH; SALMI, 2011). Os professores "devem ter consciência de sua essência internacional" (ALTBACH; SALMI, 2011, p. 20), considerando colaborar com colegas que residem em países diferentes. No que se refere às jornadas de trabalho destes docentes, elas devem ser 'modestas', para que a maior parte do tempo possa ser dedicada às atividades de investigação. A disponibilidade para mobilidade, a procura por melhores condições de trabalho e por carreiras mais promissoras também são colocadas como características deste perfil de profissional, avaliadas de forma positiva.

Corroboramos, então, com Silva Júnior (2017) ao afirmar que se intenta transformar o docente em um captador de recursos ou gestor de projetos, reconfigurando o próprio conceito de docência e pesquisa. Nessa posição, busca-se vender seus serviços de alta potência para o patenteamento, e o licenciamento e sua gestão são utilizados para a diferenciação quanto às demais instituições.

\section{Financiamento elevado e gestão flexível}

Considerando as características apontadas por Salmi (2009), as UCM são reconhecidas por amealhar uma quantia alta e diversificada de recursos. Estas instituições podem ter, a princípio, quatro fontes de receitas, a saber: 1) as ligadas à natureza institucional; 2) as que estão articuladas às formas de gestão universitária; 3) as de fundos de endowment e 4) aquelas obtidas com o financiamento de pesquisas.

De modo geral, os documentos analisados defendem que as UCM podem contar com verbas provenientes de agências públicas fomentadoras e de financiamentos de projetos de pesquisa e desenvolvimento. Percebemos que a tendência do estreitamento da relação público-privada, no tocante ao financiamento, é justificada pela necessidade de complementação financeira, como decorrência da capacidade limitada dos governos, pelo aumento das oportunidades educativas, pela necessidade de criar formas mais eficazes de gerir o financiamento público e pela possibilidade de incremento da eficiência e da inovação tecnológica.

\begin{tabular}{l|c|c|c|c|c|c} 
() Rev. Educ. Perspec. & Viçosa, $M G$ & v.9 & n.1 & p.241-258 & maio/ago. 2018 & eISSN 2178-8359 \\
\hline
\end{tabular}


Neste sentido, concordamos com Sguissardi (2009) no entendimento que a diversificação das fontes de financiamento e outros mecanismos de aproximação com o setor privado vêm transformando a universidade em um espaço cada vez mais permeável à influência de setores externos, que assim conquistam cada vez mais poder para definir a agenda universitária.

Cabe frisar que, para além do imperativo da diversidade de financiamento, os OIs e seus experts são uníssonos sobre a necessidade de financiamento por parte dos governos, ou seja, sobre a concentração dos recursos governamentais em IES selecionadas.

O modelo de UCM apresentado exige recursos e gestão que incentivem a visão estratégica, a inovação, a flexibilidade e a autonomia, para permitir que as instituições possam gerir os recursos sem serem prejudicadas pela burocracia (SALMI, 2009; SADLAK; CAI, 2009). Assim, o modelo burocrático, a equidade de salários, a estabilidade da carreira e a falta de liberdade das instituições no âmbito da gestão são consideradas características que comprometem o alcance do status de UCM. Isso denota que a autonomia universitária se reduz à gestão de receitas e despesas. Significa, portanto, gerenciamento empresarial da instituição com vistas ao atendimento de metas e indicadores impostos pelo contrato de gestão na perspectiva do mercado, das organizações sociais.

De acordo com o documento da Unesco (SADLAK; CAI, 2009), os governos precisam capacitar e incentivar as suas universidades a competir em nível internacional para atingir uma série de indicadores em que a qualidade e a relevância da educação universitária são comumente avaliadas (incluindo reputação e prêmios, estudantes e professores estrangeiros e bolsas de investigação). Para facilitar a materialização desta lógica, a autonomia de gestão, a meritocracia e a interação com o setor privado são as alternativas apontadas pelo documento.

Outro elemento fulcral para a gestão das UCM preconizado nos documentos é a necessidade de equipes de gestão coordenadas e capacitadas. Prescreve-se que seus líderes devem ter uma visão estratégica acerca das metas e dos valores da universidade e saber como implantar as medidas necessárias para atender aos objetivos institucionais, ajustando interesses de discentes, docentes e de outros profissionais afiliados às universidades (ALTBACH; SALMI, 2011).

Como apontam Altbach e Salmi (2011) em documento publicado pelo BM, o planejamento dessas instituições deve ser orientado não apenas por estratégias de atuação global, que vão além de ações que estimulem os programas de cooperação internacional, mas também pelo que diz respeito à competitividade com outras universidades de pesquisa. Por isso, em geral, os quadros de liderança desses estabelecimentos devem ser compostos por profissionais que dominem conhecimentos na área da administração de empresas, gestão universitária, inovação, empreendedorismo e política internacional.

\begin{tabular}{l|c|c|c|c|c|c} 
() Rev. Educ. Perspec. & Viçosa, $M G$ & v.9 & n.1 & p.241-258 & maio/ago. 2018 & eISSN 2178-8359 \\
\hline
\end{tabular}


Isso significa que os reitores devem ser administradores profissionais e a gestão acadêmica subordinada à racionalidade econômica. De acordo com o documento publicado pela Unesco (SADLAK; CAI, 2009), em alguns casos, as autoridades universitárias também consideraram útil a contratação de um profissional estrangeiro para liderar a instituição, a exemplo do que fizeram a Coreia do Sul, o Reino Unido e a Austrália, países em que essa estratégia vem sendo praticada há alguns anos.

Para Silva Júnior (2015), autor que investigou as UCM dos EUA, o modelo de gestão em voga consiste na separação da administração dos recursos e o processo/administração de formação de profissionais, pesquisadores e de produção da pesquisa. Neste sentido, para o autor, "as consequências deste movimento são evidentes quanto à gestão, à pauta de pesquisa, ao trabalho do professor, aos tipos de cursos de graduação e pós-graduação e à necessidade da publicação em revista de prestígio mundial [...]" (SILVA JÚNIOR, 2015, p. 150). Como resultado, as organizações vêm buscando incessantemente novas ferramentas de gerenciamento, que as direcionem para uma maior competitividade por meio da qualidade e produtividade de seus produtos, processos e serviços.

Tendo em vista o exposto, constata-se que as mudanças no âmbito da gestão apresentadas pelos OIs como essenciais ao modelo de UCM já estão sendo implementadas em instituições de educação superior de vários países, de forma mais ou menos avançada, a depender das especificidades de cada contexto.

\section{Transferência de tecnologia e inovação}

A inovação e a transferência de tecnologia também são pontos expressivos nas orientações dos OIs para uma UCM, especialmente pela OCDE. Este discurso está fundamentado pela lógica de que há um gargalo a ser resolvido no que tange à interação da universidade e o setor produtivo, considerando que a inovação é apresentada como o motor crucial da produtividade e da prosperidade econômica.

Cabe considerar que o tema inovação não expressa exatamente uma 'novidade'. O próprio Marx (2012) explica que a principal força motriz da história é a necessidade que a sociedade possui de desenvolver suas forças produtivas, ou seja: aumentar o conhecimento e o domínio sobre a natureza, reduzir o tempo de trabalho socialmente necessário para produzir e reproduzir as condições de vida, melhorar o estilo e os padrões de vida. Desse modo, devemos considerar que a inovação é resultado do intelecto humano e da vida em sociedade, antes de ser vista como subproduto do capitalismo. 
Todavia, de acordo com Harvey (2011), no atual estágio de desenvolvimento do sistema capitalista a inovação torna-se, cada vez mais, elemento-chave para a competitividade e também um negócio. Neste sentido, o autor explica que:

A competição feroz [...] tende, portanto, a produzir inovações de salto de qualidade, que muitas vezes levam os capitalistas a fetichizar a inovação tecnológica e organizacional como a resposta para todas as suas orações [...]. Esse fetichismo é alimentado à medida que a inovação se torna um negócio que visa formar seu próprio mercado, convencendo todos e cada um de nós de que não podemos sobreviver sem ter o mais recente gadget parafernália sob nosso comando (HARVEY, 2011, p. 81, destaque nosso).

Em consonância com esta compreensão, percebemos nos documentos analisados que "as universidades, particularmente aquelas consideradas 'de classe mundial', ocupam um lugar especial na cadeia de inovação". Neste sentido, elas "se tornam cada vez mais pontos focais de financiamento específico, cujo alcance real não é suporte da pesquisa acadêmica por si, mas serve de catalisador para a geração de inovações técnicas" (SADLAK; CAI, 2009, p. 15).

Compreendemos, pois que a argumentação sustentada pelos OIs está fundamentada na noção de que as universidades são convocadas a responder cada vez mais rapidamente às demandas do setor produtivo e, preconiza-se, devem fazê-lo por meio do financiamento em pesquisas em áreas estratégicas, de parcerias com o setor privado e da criação de centros de excelência. Assim, a necessidade constante de inovações para o aumento da competitividade dos países traduz-se no consenso pela excelência, pelo incentivo à promoção de UCM em detrimento das demais instituições que não apresentem 'vocação' para a pesquisa.

\section{A PROLIFERAÇÃO DE INICIATIVAS DE EXCELÊNCIA E A BUSCA PELO STATUS DE CLASSE MUNDIAL}

Consoante ao acima exposto, o modelo de UCM é utilizado pelos agentes sociais de decisão como um arquétipo com o qual se induz a competitividade internacional e eleva-se ao paroxismo a diferenciação/hierarquização entre as universidades - bem como entre áreas estratégicas no seu interior - em diferentes escalas. Nessa corrida pela excelência, da qual participam países, blocos, grupos e universidades, está a necessidade de o capital garantir que o trabalho tradicionalmente realizado nos países mais avançados seja feito de forma qualificada e flexível também nos países considerados 'emergentes'.

Nesse contexto, percebemos que projetos e iniciativas de excelência foram implementados/as em diversos países, como Alemanha (Programa Iniciativa de Excelência), França (Operação Campus), Espanha (Campus de Excelência Internacional), Reino Unido (Estrutura de Excelência da Pesquisa), China (Projetos 985, 211 e 2011), Rússia (Projeto 5-100), entre

\begin{tabular}{l|c|c|c|c|c|c|} 
() Rev. Educ. Perspec. & Viçosa, $M G$ & v.9 & n.1 & p.241-258 & maio/ago. 2018 & eISSN 2178-8359 \\
\hline
\end{tabular}


outros. Somando-se a esses países, a própria União Europeia (UE), com o "Programa Horizonte 2020" iv , lançado em 2014 e, mais recentemente, os países que compõe o BRICS (Brasil, Rússia, Índia, China e África do Sul), com a "Universidade em Rede do BRICS", lançado em 2015, também passaram a desenvolver estratégias para promover a "excelência das suas universidades", buscando o objetivo de alcançar melhores resultados nos rankings internacionais.

Tais projetos e iniciativas têm como característica comum a concentração de financiamento e esforços em algumas instituições já bem avaliadas pelos rankings e/ou com potencial para alcançar melhores posições, o que indica que a lógica operacionalizada pela concepção de UCM tem vigorado.

No Brasil, destacamos o lançamento, em 2012, do Programa "Top 200: Universidades de Excelência". Por meio deste elencava-se universidades federais para as quais os esforços e investimentos seriam concentrados, almejando a conquista da excelência, uma vez que uma das metas era a de que essas universidades ocupassem um lugar de destaque nos rankings acadêmicos internacionais. Foram selecionadas inicialmente as Universidades Federais do Rio Grande do Sul (UFRGS), de Minas Gerais (UFMG), do Rio de Janeiro (UFRJ), de São Paulo (Unifesp) e de Viçosa (UFV).

Todavia, apesar de a iniciativa não ter avançado no seu formato original, ações e projetos em busca da 'excelência universitária' têm se tornado um componente marcante da política governamental brasileira. Em retrospectiva, pode-se observar que a necessidade de criação e consolidação de centros de excelência já está posta no "Livro Branco de Ciência e Tecnologia e Inovação" e no "Livro Azul da Ciência e Tecnologia e Inovação". Convém salientar ainda o avanço nas discussões e ações no sentido da internacionalização da educação superior, especialmente a partir de 2010, com o Programa Ciências sem Fronteiras (CsF) e o incremento nas relações internacionais via pós-graduação stricto sensu, com o Programa de Estágio Doutoral no Exterior (PSDE), apesar de algumas dessas ações estarem atualmente em vias de reorganização/extinção.

Ainda identificamos como delineamentos da excelência: o Instituto Nacional de Ciência e Tecnologia (INCT); o Programa de Excelência Acadêmica (Proex/Capes) e os próprios Planos Nacionais de Pós-Graduação (VI PNPG 2011-2020) e de Educação (PNE 20142024) ${ }^{\mathrm{vi}}$. A título de possibilitar uma melhor visualização dessa 'tendência para a excelência', que se refere a um dos polos do processo de expansão e diferenciação da educação superior, na figura a seguir demonstra-se como os elementos mencionados anteriormente relacionamse: 


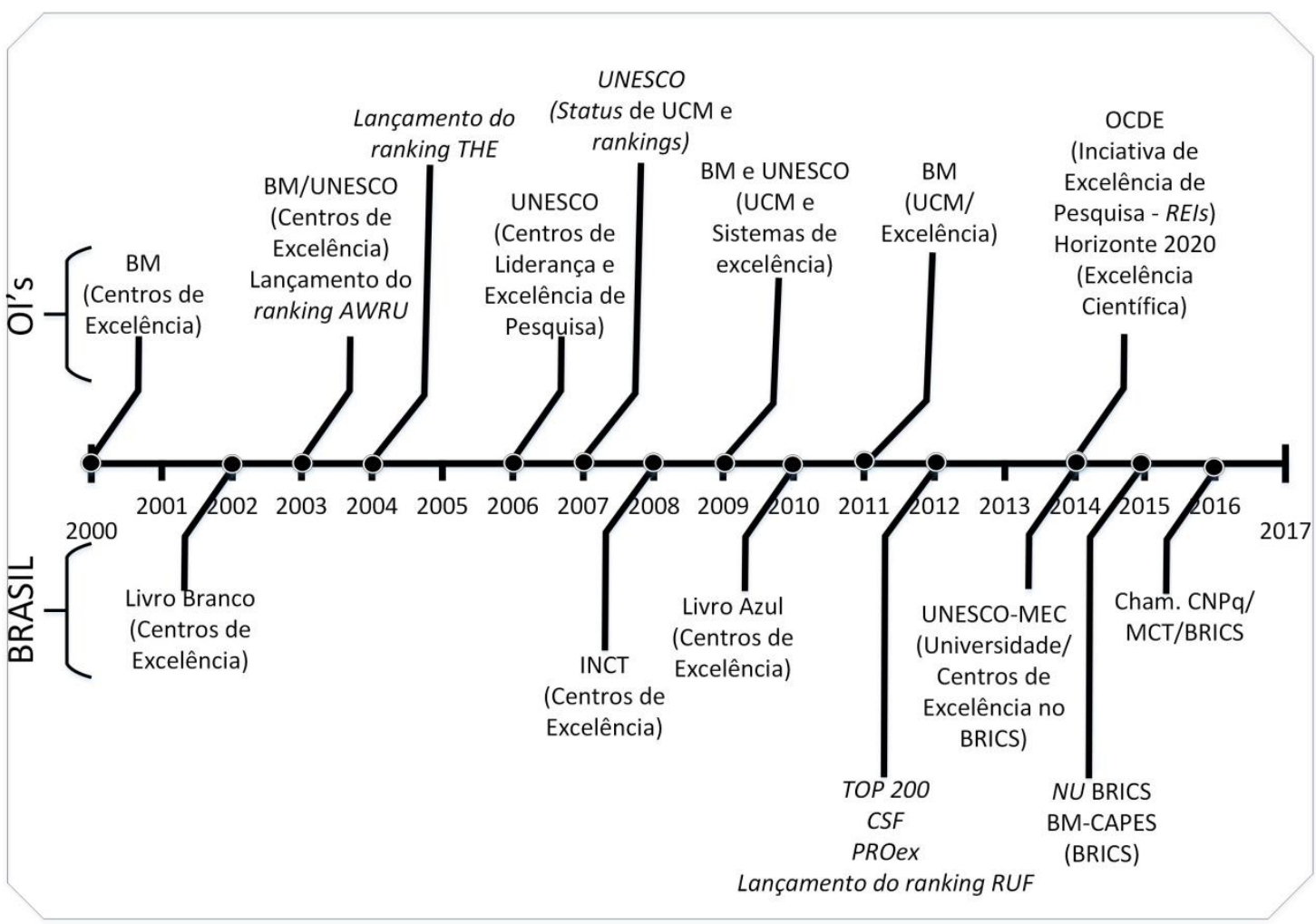

Figura 2. Linha do tempo da 'excelência'

Fonte: Thiengo (2018).

No plano institucional, percebemos que o consenso pela excelência adquire delineamentos nos Planos de Desenvolvimento Institucional (PDI) de algumas IES brasileiras, que apresentam como objetivo tornarem-se 'Universidades de Excelência', de 'Classe Mundial' ou de 'Nível internacional' ambicionando situar-se entre as melhores universidades do Brasil e do mundo. São elas: Universidade de São Paulo (USP), Universidade Federal do Rio Grande do Sul (UFGRS), Universidade Federal de Minas Gerais (UFMG), Universidade Federal de São Paulo (Unifesp), Universidade Federal do ABC (UFABC), Universidade Estadual de Campinas (Unicamp), Universidade de Brasília (UnB) e Universidade Federal de Santa Catarina (UFSC) (THIENGO, 2018). A figura 3 e os exemplos que a seguem fornecem algumas evidências ${ }^{\text {vii }}$ em relação à forma como esta discussão aparece nos PDI das referidas IES. 


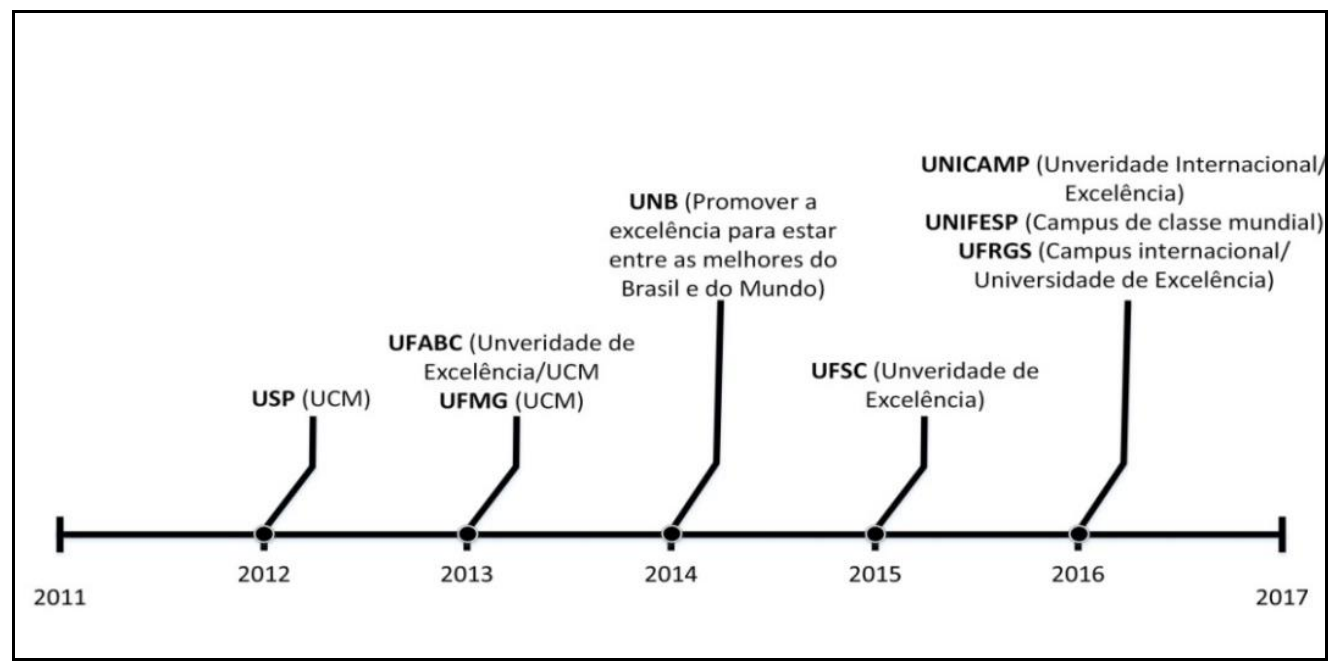

Figura 3. Linha do Tempo da excelência nos PDIs Fonte: Thiengo (2018)

O PDI da UFMG apresenta uma interessante definição entre as explicações que motivam os dirigentes desta IES a estabelecer como objetivo o alcance do status de UCM:

\begin{abstract}
A Universidade de classe mundial é um tipo específico e raro de instituição. Há apenas um grupo restrito e seleto dessa categoria de estabelecimento em todo mundo, que se destaca devido ao padrão aplicado às suas atividades de ensino e de pesquisa, passando, inclusive, a balizar o comportamento das demais entidades pertencentes ao meio, às quais serve de referência catalisadora (UFMG, 2013, p. 44).
\end{abstract}

O caráter diferenciado desta instituição frente às demais é colocado como algo natural, positivo e fundamental ao avanço científico e econômico do país, o que ratifica a lógica da diferenciação institucional também defendida pelos OIs. Do mesmo modo, no planejamento da USP está explícita a prioridade de atingir novos patamares de excelência, além de maneiras de melhorar os programas de inclusão. Entretanto, preconiza-se, esta última deve ocorrer "sem prejuízo da excelência acadêmica, visto que a atividade universitária pressupõe soluções imprevistas para impasses conhecidos" (USP, 2011, p. 16).

O PDI da USP pontua que a missão de uma UCM é contribuir para o desenvolvimento socioeconômico e sustentável do país, o que vai ao encontro da concepção defendida pelos OIs de que algumas instituições passam a assumir o papel de 'carro-chefe' em seus países. A mesma ideia também faz parte da missão das universidades que se intitulam ou almejam conquistar o status de Classe Mundial. No PDI da UFRGS, por exemplo, consta que é missão desta IES: "Desenvolver educação superior com excelência e compromisso social, formando indivíduos, gerando conhecimento filosófico, científico, artístico e tecnológico, capazes de promover transformações na sociedade" (UFRGS, 2016, p. 12). 
Nessa perspectiva, é importante salientar a argumentação presente nos PDI em defesa das UCM no Brasil, a qual está fundamentada, em linhas gerais, na necessidade de desenvolvimento econômico e social do país, uma vez que o sistema de educação superior brasileiro é identificado como inadequado às demandas da sociedade.

De acordo com o PDI da UFABC (2012-2022), a excelência é um conceito relativo, uma vez que, efetivamente, revela-se apenas na comparação com os pares. Justamente por isso, “a UFABC deve acompanhar e estudar os mais diversos rankings universitários, desde as avaliações periódicas dos cursos da graduação e da pós-graduação pelo MEC e pela Capes, até os rankings internacionais de universidades de classe mundial" (UFABC, 2012, p. 20). Desse modo, "a UFABC não deve hesitar em se comparar com as melhores universidades nacionais e internacionais" (UFABC, 2012, p. 19).

Percebemos que os rankings internacionais são evocados, por um lado, para conferir credibilidade às IES, fortalecendo-as e, por outro, para argumentar sobre a necessidade de o Brasil contar com algumas das suas universidades entre as melhores do mundo, uma vez que no documento é apontado um descompasso entre a posição das universidades nas classificações e o desenvolvimento econômico do país.

No mesmo sentido, as IES têm estruturado e implementado estratégias para que seus trabalhos científicos tenham maior visibilidade internacional, de forma a dialogar com as pesquisas de ponta que se realizam no cenário internacional. Por isso, em todos os PDI são estruturadas ações que visam incentivar a publicação de trabalhos em periódicos classificados com altos índices de impacto, além de financiar traduções e revisões para o inglês, língua acadêmica das UCM, oferecer cursos de inglês e redação científica para as universidades, atrair pesquisadores nacionais e internacionais de 'alto nível' e estimular a participação e constituição de programas de cooperação internacionais.

Observamos, então, o aprofundamento das transformações da educação superior, que já estão em processo há pelo menos três décadas e aparecem agora, no Brasil, sob nova roupagem, ainda mais elitista. Como afirma Silva Júnior (2017), trata-se de um alinhamento de um núcleo de universidades brasileiras aos preceitos do modelo de $\mathrm{UCM}^{\text {viii }}$.

\section{À GUISA DE CONCLUSÃO}

Embora com a parcialidade que sempre deve caracterizar análises de temáticas complexas em processo, compreendemos que o modelo de UCM passa a ser o representante do ideário hegemônico contemporâneo e vem servindo de modelo institucional 'exemplar', símbolo de

\begin{tabular}{l|c|c|c|c|c|c} 
() Rev. Educ. Perspec. & Viçosa, $M G$ & v.9 & n.1 & p.241-258 & maio/ago. 2018 & eISSN 2178-8359 \\
\hline
\end{tabular}


modernização e desenvolvimento, incumbido de produzir e exportar conhecimento, seus modelos de fazer ciência, distribuir recursos e avaliar.

Neste sentido, apreendemos que o modelo de UCM ora analisado implica deflagração das diferenciações na oferta de educação superior, que reforçam uma lógica excludente, mascarada pela falsa democratização do acesso e pela meritocracia. Se, por um lado, o nível de certificação em massa é dirigido a uma parcela da classe trabalhadora, para que possa agir nos espaços tecnicamente menos exigentes, por outro, a certificação, especialmente na pósgraduação stricto sensu e na pesquisa, predominantemente na aplicada, tende a estar a serviço de negócios nacionais e internacionais. Esta dimensão é destinada aos melhores alunos das melhores universidades, de modo a corroborar a diferença de classe a partir do acesso a diferentes tipos de educação, bem como pelos distintos papéis que estes estudantes virão a ocupar no mundo do trabalho e na gestão público-privada.

Este entendimento, contudo, é obnubilado pelo discurso da excelência, o qual, ao nosso ver, pode ser considerado uma ideologia. Com base no referencial teórico gramsciano, apreendemos que a 'Ideologia da excelência' manifesta-se a partir: a) da construção de símbolos de identificação positiva e da adoção de um referencial de padrão partilhado (o 'selo' da excelência); b) da utilização de representações parciais como se fossem de interesse geral; c) da recorrência de narrativas que buscam ratificar a importância da universidade de excelência ('os casos de sucesso'); d) da sustentação de relações de dominação por meio de sua negação ou ofuscação; e) da segmentação dos indivíduos em grupos, a partir de argumentos meritocráticos (talentos e não talentos/produtivos e não produtivos); f) da diferenciação da educação superior, embora nominada como diversificação; g) do ocultamento do caráter sócio-histórico das ações, ao pretender fazer com que estas iniciativas, apesar de seu caráter transitório, sejam apresentadas como permanentes, necessárias e 'salvadoras'; h) da compreensão da ciência e, especialmente, da inovação como solucionadoras dos problemas sociais, mascarando as relações capital-trabalho.

A análise empreendida, então, permite constatar a emergência e a propagação do modelo de UCM, fundamentado na 'Ideologia da Excelência', como expressão do aprofundamento da diferenciação da/na educação superior e da rendição ao mercado, em patamares impensáveis até há pouco, sendo esta uma tendência que ganha força em detrimento da concepção de universidade enquanto universitas.

\section{REFERÊNCIAS}

ALTBACH, Philip et al. Trends in Global Higher Education: tracking an academic evolution. Boston: Sense Publishers, 2010.

\begin{tabular}{l|c|c|c|c|c|c} 
(C) Rev. Educ. Perspec. & Viçosa, $M G$ & v.9 & n.1 & p.241-258 & maio/ago. 2018 & eISSN 2178-8359 \\
\hline
\end{tabular}


ALTBACH. Philip; SALMI, Jamil. El camino hacia la excelencia académica: la constitución de Universidades de Investigación de Rango Mundial. Tradução para o espanhol: Ediciones Gondo e Banco Mundial. Washington, EUA: Banco Mundial, 2011.

CARNOY, Martin. et al. Expansão das Universidades em uma economia global em mudança: um triunfo dos BRIC? Brasília: Capes, 2016.

CHESNAIS, François. A mundialização do capital. São Paulo: Xamã, 1996.

GRAMSCI, Antonio. Cadernos do cárcere: os intelectuais; o princípio educativo; jornalismo. 6. ed. v. 2. Rio de Janeiro: Civilização Brasileira, 2011.

HARVEY, David. O enigma do capital: e as crises do capitalismo. São Paulo: Boitempo, 2011.

MARX, Karl. O Capital. Crítica da Economia Política. O Processo de Produção do Capital. Livro 1, Volume 1. 3. ed. Rio de janeiro: Civilização Brasileira, 2012.

OCDE. Organização para a Cooperação e Desenvolvimento Económico ou Econômico. Promoting Research Excellence: New Approaches to Funding. Paris, França: OECD, 2014.

SALMI, Jamil. El desafío de crear universidades de rango mundial. Colômbia: Mayol Ediciones, BM, 2009.

SADLAK, Jan.; CAI, Liu Nian (Editores). The World-Class University as Part of a New Higher Education Paradigm: From Institutional Qualities to Systemic Excellence. Bucharest, Romênia: UNESCO-Cepes, 2009.

SILVA JÚNIOR, João do Reis. The new brazilian university - A busca de resultados comercializáveis: para quem? Relatório de Pesquisa FAPESP/CNPQ. São Carlos: UFSCAR; Tempe/Phoenix, EUA: ASU, 2015.

SILVA JÚNIOR, João do Reis. The new brazillian university. A busca de resultados comercializáveis: para quem? Bauru: Canal 5, 2017.

SGUISSARDI, Valdemar. Universidade brasileira no século XXI. Desafios do presente. São Paulo: Cortez, 2009.

SGUISSARDI, Valdemar. Estudo Diagnóstico da Política de Expansão da (e Acesso à) Educação Superior no Brasil - 2002-2012. Brasília: Edital N. 051/2014 SESU. Projeto de Organismo Internacional - OEI; Projeto OEI/BRA/10/002, 2014.

THIENGO, Lara Carlette. Universidades de Classe Mundial e o consenso pela excelência: tendências globais e locais. 2018. 366f. Tese (Doutorado em Educação). Programa de PósGraduação em Educação da Universidade Federal de Santa Catarina (UFSC), Florianópolis, 2018.

\begin{tabular}{|c|c|c|c|c|c|c} 
(C) Rev. Educ. Perspec. & Viçosa, $M G$ & v.9 & n.1 & p.241-258 & maio/ago. 2018 & eISSN 2178-8359 \\
\hline
\end{tabular}


USP. Universidade de São Paulo. Plano de Desenvolvimento Institucional 2012-2017. São Paulo, 2011.

UFMG. Universidade Federal de Minas Gerais. Plano de Desenvolvimento Institucional 2013-2017. Belo Horizonte, 2013.

UNIFESP. Universidade Federal de São Paulo. Plano de Desenvolvimento Institucional 2016-2020. 2016.

UFABC. Universidade Federal do ABC. Plano de Desenvolvimento Institucional 20122022. São Paulo, 2012.

UFRGS. Universidade Federal do Rio Grande do Sul. Plano de Desenvolvimento Institucional 2016-2026. 2016. Porto Alegre, 2016.

UNESCO. BRICS. Construir a educação para o futuro. Brasília, 2014.

\section{NOTAS}

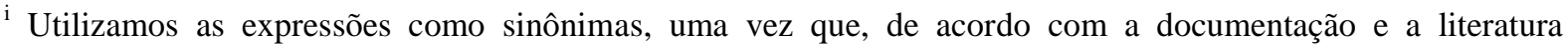
consultadas, ambas dizem respeito a um mesmo conjunto central de características desse modelo/concepção de universidade.

${ }^{\text {ii }}$ Ressaltamos que todas as traduções de excertos do inglês e do espanhol são de responsabilidade do/a autor/a.

iii Pode ser traduzida como "Iniciativas de Excelência em Pesquisa".

iv O "Programa Horizonte 2020", parte da Estratégia Europa 2020, é o maior programa-quadro de financiamento para investigação da história da União Europeia. Está fundamentado em três pilares: excelência científica, liderança industrial e desafios societais. Com orçamento de aproximadamente 80 bilhões de euros, financia projetos de investigação e inovação em áreas estratégicas tendo como principal objetivo a produção de inovação.

${ }^{\vee}$ É um projeto educacional que visa desenvolver, preferencialmente e no curto prazo, formação e investigação bilateral/multilateral por meio de programas de pós-graduação conjuntos, dessas universidades, em vários campos do conhecimento.

vi Também podem ser considerados indicadores da discussão: a publicação pela Coordenação de Aperfeiçoamento de Pessoal de Nível Superior (Capes), em parceria com o Banco Mundial, do livro "Expansão das Universidades em uma economia global em mudança. Um triunfo dos BRIC?" (CARNOY et al. 2016) e a publicação do livro/documento "BRICS. Construir a educação do futuro" em parceria com a Unesco (UNESCO, 2014).

vii Considerando os limites deste texto, apresentamos apenas algumas questões centrais. Em Thiengo (2018), analisa-se o conjunto de PDI das referidas IES com maior rigor e detalhes.

viii Em novembro de 2017 foi anunciado pelo Ministério da Educação (MEC) a proposta da criação de um Fundo Público para universidades de excelência no Brasil, atrelado ao Programa de Excelência de Universidades e Institutos. Ao que parece, o componente fundamental do fundo e do Programa de Excelência é a tentativa de aprofundar a internacionalização da pesquisa brasileira e integrá-la mais diretamente ao setor produtivo nacional.
}

\begin{tabular}{l|c|c|c|c|c|c} 
(C) Rev. Educ. Perspec. & Viçosa, $M G$ & v.9 & n.1 & p.241-258 & maio/ago. 2018 & eISSN 2178-8359 \\
\hline
\end{tabular}




\section{Sobre s autores}

${ }^{1}$ Lara Carlette Thiengo - Universidade Federal de Santa Catarina - E-mail:

laracarlette@gmail.com- ORCID: http://orcid.org/0000-0003-3593-4746

${ }^{2}$ Lucídio Bianchetti - Universidade Federal de Santa Catarina -

E-mail: lucidio.bianchetti@pq.cnpq.br - ORCID: http://orcid.org/0000-0001-9748-5646 